\title{
O PROCESSO DE INTERNACIONALIZAÇÃO DA EDUCAÇÃO E SEUS REFLEXOS PRÁTICOS E TEÓRICOS SOBRE AS POLÍTICAS EDUCACIONAIS
}

\begin{abstract}
THE PROCESS OF INTERNATIONALIZATION OF EDUCATION AND ITS PRACTICAL AND THEORETICAL REPURCUSSIONS ON EDUCATION POLICIES

EL PROCESO DE INTERNACIONALIZACIÓN DE LA EDUCACIÓN Y SUS REFLEJOS PRÁCTICOS Y TEÓRICOS SOBRE LAS POLÍTICAS EDUCACIONALES
\end{abstract}

Altair Alberto Fávero ${ }^{1}$

Evandro Consálter ${ }^{2}$

${ }^{1}$ Doutor em Educação pela UFRGS. Docente do Programa de Pós-Graduação em Educação da Universidade de Passo Fundo (UPF) - Passo Fundo - RS - Brasil. ${ }^{2}$ Mestre em Educação pela Universidade de Passo Fundo (UPF) - Passo Fundo - RS - Brasil.

O contexto da internacionalização das políticas educativas e os seus reflexos sobre o ensino básico e superior têm ganhado o olhar de pesquisadores das mais importantes universidades nacionais e internacionais. Diante deste contexto, as investigações e as discussões sobre essa temática na Linha de Pesquisa Políticas Públicas e Gestão da Educação, do Programa de Pós-Graduação em Educação da Universidade de Brasília (PPGE/UnB), deram origem à obra Internacionalização da Educação: discursos, práticas e reflexos sobre as políticas educativas. O livro integra a coletânea Políticas Públicas de Educação, que em 2016 alcançou a marca de 34 títulos.

A coletânea em questão reúne artigos de pesquisadores brasileiros e estrangeiros que se dedicam à investigação da internacionalização das políticas educativas, no âmbito da educação básica e do ensino superior. Está dividida em três partes, sendo a primeira intitulada "Internacionalização da Educação e Construção de Territórios Acadêmicos", composta por cinco artigos. A segunda parte, nominada "Orientações políticas e impactos do PISA nas práticas educativas", reúne três artigos. Por fim, a terceira parte, formada por mais três artigos, tem a nomenclatura "Cenários da avaliação na política supranacional do Mercosul".

O primeiro artigo da coletânea, de autoria de Maria Luiza de Santana Lombas e Fernanda Antônia da Fonseca Sobra, tem como título "Brain circulation e a internacionalização da produção do conhecimento: a experiência brasileira". O texto faz uma abordagem crítica acerca dos possíveis efeitos da circulação acadêmica transnacional para a internacionalização da produção do conhecimento. A base de análise para o estudo parte de uma investigação sobre os percursos adotados por doutorandos brasileiros, subsidiados pelo governo federal, em pesquisas no exterior.

O segundo artigo da primeira parte tem como título "Euromime: Conectando territórios acadêmicos com vistas à promoção de inovações na produção de conhecimentos". De 
autoria de Gilberto Lacerda dos Santos, Thomas Petit e José Vieira de Sousa, o texto traça uma análise da contribuição do Consórcio Europeu de Engenharia de Mídias para a Educação (Euromime) para a estimulação de práticas inovadoras no contexto da educação superior. A análise tem foco nas tecnologias interativas e conectoras desenvolvidas para as sete universidades que compõem o consórcio, tendo em vista a internacionalização de suas práticas educativas.

Com o título "A educação superior em tempos de internacionalização: cinco mitos, nove enganos e cinco verdades", o texto do professor Mário Luíz Neves de Azevedo propõe uma melhor compreensão de alguns mitos e equívocos acerca da internacionalização da educação superior. Além disso, recorrendo à categoria da contradição, o texto aborda cinco verdades a respeito do tema investigado. Conforme o autor, "analisar a internacionalização da educação superior é avançar sobre um terreno de lutas em que o próprio conceito de internacionalização está em disputa" (p.75).

Também integrando a primeira parte da obra, o estudo de Marília Costa Morosini e Antônio Pedro Barbosa Cardoso, intitulado "O sistema de avaliação do Ensino Superior de Cabo Verde: questões da internacionalização Sul-Sul", propõe uma análise e compreensão da percepção de especialistas, pesquisadores e gestores de instituições de ensino superior de Cabo Verde acerca da criação e da implementação do sistema de avaliação do ensino superior nesse país. Os autores tecem a análise sobre esse sistema avaliativo no referido arquipélago, partindo do pressuposto de que, em nível de globalização, Estado-nação e instituição, a avaliação da educação superior assume papel central como um dos instrumentos de materialização das políticas públicas para a educação.

Por fim, o último texto da primeira parte da coletânea tece uma análise acerca das políticas de educação infantil implementadas sob a lógica do Banco Mundial e as concepções de infância que permeiam essas políticas. De autoria de Fani Quitéria Nascimento Rehem, com o título "Infâncias subsumidas: políticas públicas e a formação de capital humano em questão", o texto também analisa essa temática a partir de três enfoques: no primeiro deles, aborda a categoria marxiana subsunção como fundamental para a explicação da lógica que imprime a elaboração das políticas públicas eleitas para discussão; no segundo, elege para discussão as interferências do Banco Mundial na gestão dos serviços sociais, entre eles, a educação; por fim, no último enfoque, realiza uma problematização acerca da história dessas políticas para a infância e sua relação com a construção do capital humano do futuro.

A segunda parte da coletânea tem como temática as orientações políticas e os impactos do PISA nas práticas educativas e é composta por três textos. O primeiro deles, com o título "A educação fotografada pelo PISA e difundida pela OCDE", de autoria de Maria Abádia da Silva e Rogério da Silva Pereira, faz uma análise acerca das relações entre o governo federal e a Organização para Cooperação e Desenvolvimento Econômico (OCDE) no que diz respeito às questões como a ideologia construída em torno da sociedade do conhecimento e suas materializações nas políticas para a educação básica, os conceitos de qualidade difundidos pelo PISA e como o Plano Nacional de Educação (PNE) compreende o conceito de qualidade na educação básica. 
O segundo texto desta seção é de autoria de Luis Miguel Carvalho e Estela Costa, tendo como título "Comparações internacionais do desempenho escolar e políticas educativas: síntese de uma investigação". O estudo analisa as relações entre o conhecimento pericial e a regulação da educação, centrando-se na análise dos processos de fabricação, circulação e mobilização, no curso da ação pública de um programa de comparação internacional em conformidade com as diretrizes da OCDE.

O último texto desta segunda parte do livro é de autoria do professor da Universidade de Salamanca, Leoncio Vega Gil. Com o título "Los cuasi-estados de la educación en España y la eficacia del sistema escolar, según PISA: reduciendo la equidad y aumentando las diferencias", o autor realiza um debate acerca do modelo educativo espanhol considerando a aplicação das políticas do governo do Partido Popular, adotadas a partir de 2014. Conforme o estudo de Vega Gil, o sistema educacional espanhol orienta suas tendências qualitativas e formativas a partir dos resultados da avaliação do PISA. Diante desse cenário, as reflexões propostas pelo texto objetivam ampliar as discussões acerca desta temática no contexto das políticas educativas.

Por fim, a terceira parte da coletânea, também composta por três textos, aborda os cenários da avaliação na política supranacional no contexto do Mercosul e de seus países membros. O texto "A avaliação no contexto da política supranacional: efeitos na educação superior brasileira", de autoria de Giselle Cristina Martins Real e Verônica de Lourdes Pieto Oliveira, realiza um estudo acerca do Sistema de Acreditação Regional de Cursos de Graduação do Mercosul (ARCU-SUL), com o objetivo de identificar os possíveis efeitos das iniciativas supranacionais voltadas para a avaliação da educação superior na política brasileira. Para elucidar a investigação, as autoras dividem o texto em três seções: na primeira analisam o papel do Mercosul na elaboração de políticas supranacionais para a educação; na segunda realizam um enfoque a partir das iniciativas de avaliação da educação superior no Mercosul; e, por fim, analisam os efeitos das iniciativas supranacionais nas políticas educacionais para a educação superior no Brasil.

Dando sequência à temática desta terceira parte da coletânea, o texto das professoras Cláudia Maffini Griboski e Suzana Schwerz Funghetto faz uma abordagem da internacionalização como suposto indicador de qualidade. Intitulado de "A internacionalização como indicador de qualidade do Sinaes e do Sistema Arcu-Sul", o estudo parte da premissa de que, no Brasil, o Sistema Nacional de Avaliação da Educação Superior (Sinaes) tem estimulado o desenvolvimento da internacionalização como critério de qualidade. O estudo mostra o direcionamento de que os critérios de qualidade estão diretamente relacionados ao fortalecimento de intercâmbios e de mobilidade acadêmica entre os países membros e associados do Mercosul.

O último texto do livro reserva espaço para uma análise da realidade brasileira e argentina da formação de gestores para o ensino básico e educação em direitos humanos. O texto é de autoria das professoras Kátia Silveira de Freitas e Ailana Freitas Rocha, tendo como título "Políticas de formação de dirigentes escolares para o ensino básico no Brasil e na Argentina e Educação em Direitos Humanos". O estudo, realizado a partir da análise de dois cursos de pósgraduação latu sensu realizados no Brasil e na Argentina, voltados à formação de dirigentes 
para a educação básica, aborda a fragilidade dos professores em relação ao conhecimento do conjunto de políticas educacionais do Setor do Mercado Comum do Sul (SEM-MERCOSUL).

Num olhar panorâmico no conjunto da obra Internacionalização da Educação: discursos, práticas e reflexos sobre as políticas educacionais, pode-se dizer que a coletânea se constitui numa rica e importante contribuição para a discussão da internacionalização das políticas educacionais, sobretudo no contexto do Mercosul. Compreender essa realidade é de fundamental importância para que se possa aprofundar os estudos teóricos e epistemológicos das políticas educacionais, as conjunturas que as geram e lançar olhares sobre futuros desafios políticos da educação no contexto contemporâneo de globalização e da expansão do ensino superior.

\section{REFERÊNCIA}

CUNHA, C. da; SOUSA, J. V. de; SILVA, M. A. da. (Org). Internacionalização da Educação: discursos, práticas e reflexos sobre as políticas educativas. 1. ed. Belo Horizonte - MG: Fino Traço, 2016.

Artigo recebido em: 16/02/2017

Aprovado em: 19/04/2017

\section{CONTATO PARA CORRESPONDÊNCIA:}

Altair Alberto Fávero. E-mail: altairfavero@gmail.com 